Arteterapia. Papeles de arteterapia y educación para inclusión social ISSN: 1886-6190

\title{
Cuerpo e identidad: artes visuales para una hermenéutica de la diferencia. Experiencias con maestros en formación inicial
}

\author{
Albert Macaya Ruiz ${ }^{1}$
}

Recibido: 9 de marzo de 2016 / Aceptado: 13 de junio de 2016

Resumen. Ayudar a otras personas a asumir de modo constructivo el modo en que la vivencia del cuerpo determina nuestra identidad es un reto pedagógico de primer orden. Como tal, debería ser contemplado en la escuela primaria. En este artículo presentaremos una investigación que analiza experiencias en la formación los maestros y maestras, en relación con la vivencia del propio cuerpo a través de las artes visuales. Las imágenes artísticas y el lenguaje escrito sirven a los participantes para dar sentido a su experiencia vivida, en la que afloran temas como los cánones estéticos, la diversidad funcional, la enfermedad o la lesión.

Palabras clave: cuerpo; diversidad; artes como autoconocimiento.

\section{[en] Body and identity: visual arts for a hermeneutics of difference. Experiences with teachers in initial training}

\begin{abstract}
Helping other people to assume, in a positive way, the relationship between our own body and our identity is an important pedagogical challenge. It should be considered already in the primary school. In this paper, we will summarize a research focused on the experiences introduced in the teacher training process, in order to explore the sentience of the body trough visual arts. Art images and written language have been useful for the participants to give significance to their lived experience. The process brings out subjects such as corporal aesthetic canon, functional diversity, illness or body damage.
\end{abstract}

Keywords: body; diversity; art as self-knowledge.

Sumario. 1. Introducción; 2. Docentes y pedagogía de la diferencia; 3. Cuerpo y alteralidad; 4. Representaciones del cuerpo y la diversidad: la aportación del arte contemporáneo; 5. Experiencias sobre autorrepresentación y vivencia del cuerpo; 6 . Conclusiones; 7 . Referencias bibliográficas.

Cómo citar: Macaya Ruiz, A. (2016) Cuerpo e identidad: artes visuales para una hermenéutica de la diferencia. Experiencias con maestros en formación inicial, en Arteterapia. Papeles de arteterapia y educación para inclusión social 11, 13-50.

1 Artista visual y profesor del área de Didáctica de la Expresión Plástica. Participa en docencia de grado y máster, y es miembro de un grupo de investigación consolidado por AGAUR.

albert.macaya@urv.cat 


\section{Introducción}

El binomio homogeneidad-diferencia se nos presenta, en contextos educativos, como un tema recurrente y preñado de retos pedagógicos. Quizá el ámbito en que este binomio se manifiesta de modo más claro es el que tiene que ver con nuestra apariencia externa. Todos somos diferentes: he aquí una realidad incontestable que choca a menudo (especialmente entre adolescentes, pero también en la escuela primaria) con un apenas disimulado deseo de integración y aceptación. Sin embargo, la diferencia forma parte de nuestra realidad y no podemos, simplemente, obviarla. Sin duda nos alejamos de manera progresiva de los tiempos en que algunas formas de diferencia se asociaban al déficit y se estigmatizaba torpemente a las personas, pero la vivencia del propio cuerpo es todavía un ámbito que reclama atención pedagógica.

$\mathrm{Si}$ a menudo la cultura visual circundante parece inducir a los adolescentes $-\mathrm{y}$, sobre todo, a las adolescentes- a la desafección respecto a su propio cuerpo, qué cabe decir de temas como la diversidad, la lesión o la enfermedad. Tener una relación armónica con el propio cuerpo, vivir en plenitud las posibilidades que nos brinda y asumir de modo constructivo el modo en que la vivencia del cuerpo determina nuestra identidad son retos pedagógicos de primer orden. Como tales, deben estar presentes en la educación primaria, a la que reclamamos que dé respuesta a necesidades educativas de todo tipo. Para asegurarnos de que estos temas tengan presencia en la escuela debemos incluir, en la formación inicial del profesorado, experiencias que inciten a la reflexión y al debate.

Las áreas artísticas son ámbitos especialmente idóneos a tal propósito: las manifestaciones artísticas son vehículos de autoconocimiento y autoaceptación, como una importante tradición en arteterapia se ha encargado de demostrar. En particular, encontramos argumentos a favor de las artes como autoconocimiento en los referentes teóricos que han enfatizado la importancia del componente artístico en esta disciplina (Allen, 2001; Mc Niff, 2013) o los que han destacado la relación pedagógica entre artes y emoción (Duncan, 2007), por oposición a quienes entienden las artes como un complemento de la actividad terapéutica. Un concepto ampliado de la arteterapia como autoconocimiento justifica su interés en contextos educativos más allá del ámbito clínico (López Fernández-Cao, 2006, Martínez y López Fernández-Cao, 2004).

En este artículo presentamos algunas experiencias en la formación del profesorado de educación primaria en relación con la vivencia del propio cuerpo desde las artes visuales. El sentido que persiguen estas experiencias podría definirse como de corte fenomenológico-hermenéutico. Es evidente que podemos transferir a la escuela con más sentido aquello que hemos experimentado y vivenciado por nosotros mismos. En los párrafos que siguen argumentamos la dimensión fenomenológica de la vivencia del cuerpo, tal y como ha sido formulada por algunos referentes del pensamiento contemporáneo. La vivencia, sin embargo, debe ser dotada de sentido, debe ser interpretada. Dar sentido a nuestra experiencia del cuerpo es el primer paso para establecer una relación más armónica con él. Por tanto, nos planteamos, con Van Manen (2003), la escritura y las imágenes artísticas como medios para interpretar la experiencia vivida tal y como la experimentamos. 
En la segunda parte del texto, en la descripción y análisis de la investigación, aparecen cuestiones como los cánones estéticos y su relación con los trastornos de la conducta alimentaria (TCA), la diversidad funcional, las lesiones o la enfermedad. Es preciso hacer, por tanto, un matiz relevante: no es nuestra intención equiparar temas radicalmente distintos como enfermedad, diversidad funcional o diferencia en la apariencia externa de las personas. Sin embargo, entre las participantes, ${ }^{2}$ fue en estas temáticas en las que se verificó de un modo más claro la utilidad de las artes para plantear cuestiones de calado emocional. McNiff (1992) ha utilizado la expresión autenticidad para referirse a la cualidad esencial de este tipo de manifestaciones artísticas. No son el resultado de un proceso creativo profesional, con todos los condicionantes del campo específico, sino manifestaciones genuinas de personas individuales. Como confirman los testimonios recogidos, se verifica que la propuesta artística fue efectivamente un camino para pensar e interpretar la relación con el propio cuerpo, incluyendo aspectos potencialmente conflictivos o traumáticos. Cabría citar aquí un referente "clásico" de la arteterapia como Kramer (1982), cuando nos dice que, en el acto creativo, el conflicto se reexperimenta, se resuelve y se integra.

Veremos también que muchos de los participantes declaran haber comprendido un mundo de posibilidades en la actividad artística que podrán aplicar en su futura labor como docentes. En este aspecto, el cambio de perspectiva nos remite de nuevo a McNiff (2013): como veremos, los participantes, que inicialmente pensaban en las artes como productos de grandes creadores individuales, invisten de un claro sentido de comunidad a la expresión creativa. El artista (artista-docente en este caso) entiende su quehacer como servicio a los demás, más que como creación individual al uso.

\section{Docentes y pedagogía de la diferencia}

La importancia de incluir contenidos como los que analizaremos en este artículo en la formación de los maestros podría también justificarse desde los argumentos de lo que se ha denominado pedagogía de la diferencia (Freire, 1997; Skliar, 2002; Melich y Bárcena, 2000), centrados en este caso en la vivencia del cuerpo. En este punto, hay que decir que, en el ámbito que nos ocupa, las palabras se deben utilizar con la mayor sensibilidad posible. La noción misma de "diferencia" podría, quizá, interpretarse como poseedora de un trasfondo involuntariamente segregador. Sin embargo, los autores que referenciaremos la han utilizado en su argumentación en un sentido indiscutiblemente inclusivo.

En la educación contemporánea existe una creciente consciencia de la necesidad de contrarrestar la enorme presión que nuestra cultura proyecta sobre la propia imagen. De un modo muy significativo, el cuerpo se convierte hoy en campo de batalla de múltiples fuerzas, ya sea bajo la máscara de cánones estéticos o abiertamente bajo intereses comerciales manifiestos. Es sabido que la delgadez extrema que difunden los media, particularmente la publicidad, provoca no pocos

2 En este texto utilizaremos indistintamente el masculino y el femenino como genéricos, en un intento de evitar el carácter sexista del masculino genérico, pero sin recurrir a la reiterativa distinción entre masculino y femenino en cada caso (“los alumnos y las alumnas”, p. e). 
problemas en la autoimagen de niñas y adolescentes, y puede ser uno de los desencadenantes de los TCA (Nevado, Del Río y Vallès, 2014). Sin embargo, los cuerpos supuestamente perfectos que aparecen en esos medios, a menudo resultado del milagroso "efecto Photoshop", poco o nada tienen que ver con la apariencia física de los seres humanos reales. Cada individuo es único e irrepetible: la diversidad, solemos convenir, es uno de los valores más preciados de los seres humanos. Urge, pues, una pedagogía de la diferencia.

Esta pedagogía nos debe permitir, además, superar viejas inercias en que la diferencia se asociaba al déficit, a la desviación de la norma construida, y en que se estigmatizaba a los sujetos (Goffman, 2008) Las categorizaciones y etiquetas, sin embargo, forman aún parte de nuestro paisaje social, dentro y fuera de la escuela. Skliar (2002) nos hace ser conscientes de que la atención se ha fijado a menudo en los diferentes y no en las diferencias, en la alteralidad que nos interpela como espejo de nuestra identidad. La obsesión por el diferente sería, en Skliar, una consecuencia del paradigma médico o biologicista en la modernidad. Aunque esgrimamos un discurso bienintencionado sobre la diversidad, al final los diversos son siempre los otros. En el ámbito escolar, la preocupación por la "normalidad" sería una consecuencia de la tendencia a pensar al alumno como incompleto. Tal y como ha expresado Fernández (2008), el alumno no "es", en presente y con plenas posibilidades, sino que "será", por mor de la acción pedagógica:

Esta idea se complementa con la necesidad de control de ese alumno que es un no-saber, no-pensar, no-decir, y que por lo tanto debe estar sujeto a nosotros (Skliar, 2005: 10). Tal sería el objetivo primordial de la educación, perpetuando su mandato fundante de supuesta igualación y homogeneización, suprimiendo las diferencias. (Fernández, 2008: 342)

Las críticas a la visión del alumnado como un ser en proyecto, que debe ser asimilado a unas expectativas igualadoras, entroncarían con una interesante tradición de pedagogía crítica que, como es sabido, tiene un referente esencial en Freire (1985), cuya influyente concepción de la educación emancipadora desbanca la centralidad de la normatividad, propugnando una nueva relación con el otro. Este ha sido un punto de partida inspirador para muchos posicionamientos recientes en relación con la diversidad, a los que haremos referencia más adelante.

\section{Cuerpo y alteralidad}

Cuerpo, alteralidad y diversidad han sido objeto de estudio recurrente para el pensamiento moderno y contemporáneo. Esbozaremos algunas ideas fuerza que pueden ser útiles para los propósitos de este texto. Más que un análisis exhaustivo de las relaciones entre cuerpo, diferencia y alteralidad en la historia de la filosofía, que sobrepasaría en mucho las limitaciones de este artículo, las líneas que siguen pretenden aportar algunos referentes fundamentadores y sugerentes en relación con el tema que nos ocupa.

Una perspectiva especialmente inspiradora es la que ofrece la fenomenología. Como es sabido, la fenomenología se ocupa de la experiencia vivida; propugna un retorno, en la conocida expresión de Husserl, "a las cosas mismas”. Husserl (1985, 
1931) entiende el problema de la alteralidad a partir del yo. Partiendo de la formulación descartiana que entiende el yo como única evidencia incontestable, Husserl propone una analogía que va del yo al otro. Mientras que el propio cuerpo es experiencia vivida, es experimentado como cuerpo orgánico, el cuerpo del otro es experimentado como algo exterior, físico; es un fenómeno para mí. No olvidemos que, para Husserl, es el yo quien da sentido al fenómeno: no tengo acceso a la subjetividad del otro. Realizamos, entonces, una asociación por semejanza, un movimiento analogizante: haciendo una transferencia de sentido desde el yo, inferimos que hay un yo en el cuerpo del otro. Ciertamente no tengo acceso al yo ajeno; su subjetividad se me hace com-presente. Comprendo al otro como un alter ego.

La posición de Husserl ha sido objeto de un amplio debate que no podemos desarrollar aquí en toda su complejidad, pero nos parece importante destacar la aportación de Sartre, porque introduce una perspectiva nueva que, en cierta medida, invierte los términos de la formulación husserliana. Para Sartre (2008, 1943), el yo es también objeto de la mirada del otro: el encuentro y la confrontación con el otro, a modo de espejo, determina también la percepción de mí mismo. El otro me constituye; me devuelve mi reflejo y convierte la construcción de la identidad individual en un proceso reflejo, que va, en este caso, del otro al yo.

Es fácil descubrir resonancias de gran alcance pedagógico en la formulación de Sartre. La mirada del otro, en particular de los pares, se convierte a menudo en voluntad - a veces acompañada de algún grado de angustia - de sentirse igual, de ser aceptado en el grupo. La diferencia y la diversidad en lo relativo al cuerpo aparecen en no pocas ocasiones como elementos problematizantes en este deseo de aceptación por los pares.

Indudablemente, esta voluntad de sentirse aceptado e integrado en el grupo no ha hecho más que aumentar en los últimos años. En lo que se refiere a la vivencia y la autoaceptación del propio cuerpo y la propia imagen, la pregunta clave podría ser por qué la diferencia, la diversidad, no pueden ser aceptadas sin más; por qué, en vez de reivindicar el derecho a la diferencia, no podemos limitarnos a reclamar, como señala Delgado (1998), el derecho a la indiferencia: como si nos autorizáramos a imaginar un mundo donde cada cual es como es sin provocar rechazos, sin suscitar siquiera la curiosidad ajena.

Una respuesta sugerente se derivaría de la noción de gubernamentalidad propuesta por Foucault $(2001,1978)$. Foucault nos ha mostrado cómo las relaciones de poder subyacen a la acción humana en los más diversos ámbitos. La vivencia del cuerpo y la aceptación positiva de la propia autoimagen, más aún si introducimos la variable sartreana de la mirada del otro, están en relación directa con la noción de subjetividad. Foucault (1986) nos hace tomar conciencia de que la subjetividad no es una producción individual de autoconciencia libre e indeterminada. La subjetividad es un subproducto de la relación entre el saber y el poder; el sujeto está constituido por circunstancias exteriores, es un sujeto sujetado. A finales de la década de 1970, la noción de gubernamentalidad hace más sutil si cabe la reflexión foucaultiana sobre la subjetividad (Foucault, 2001, 1978). El poder se conceptualiza como el modo de gobernar (conducir, modificar) la conducta de otros. No se plantea aquí el poder como dominación por medios 
coercitivos, según la concepción clásica: la idea no es someter a otros, sino gobernar su conducta; establecer las condiciones para que la conducta individual pueda seguir un determinado curso. Quizá la derivada más relevante para el hilo argumental de este artículo es que esta nueva perspectiva no solo se aplica al gobierno de la conducta de otros, sino al gobierno de la conducta de uno mismo.

Aquí emerge bajo una nueva luz el problema de la normatividad aplicada al cuerpo, la diversidad y la autoimagen. Toma un nuevo sentido toda la presión sobre jóvenes y adolescentes en lo relativo al cuerpo y la "normalidad" manifestada como deseo de aceptación por los pares. La mirada del otro que me constituye, según la formulación sartreana, es también un modo tácito de control, un componente esencial del gobierno de la conducta de uno mismo, un límite al "campo posible de acción" enunciado por Foucault que dificultaría o impediría ese posible "derecho a la indiferencia".

Si Foucault nos pone en guardia ante las implicaciones de la subjetividad y su relación con el cuerpo y la diferencia, cabría añadir, acaso como contrapeso, un componente de corte ético al debate. Una cuarta referencia imprescindible, que complementa las tres anteriores, sería Lévinas (1993). Después de retomar el debate husserliano sobre la alteralidad, concluye que no hay transferencia que valga desde el yo. El otro es indiscernible, es absolutamente otro; pero el otro me asigna responsabilidad. En el otro veo un rostro. Y esta es una idea clave en Lévinas: si bien vemos caras todos los días, las caras no son lo mismo que el rostro. En Lévinas, el rostro es la manifestación de un individuo particular, concreto, que se nos presenta como único e irrepetible. La cara se ve, el rostro se oye (Melich, 2010). El rostro es una demanda, nos reclama, se nos presenta como alguien que tiene cuerpo, nombre propio. Por tanto, la confrontación con ese yo individual la vivimos como una apelación a la ética: el rostro me demanda empatía, solidaridad. Me empuja a una ética de la no indiferencia ante el dolor ajeno. Las formulaciones esbozadas aquí se complementan en cierto modo. En la primera, nos ocupamos de un movimiento del yo al otro de tipo gnoseológico. En la última, de un movimiento de tipo ético. Entre las dos, constatamos que el otro me configura; la mirada va del yo al otro, pero también del otro a mí.

\section{Representaciones del cuerpo y la diversidad: la aportación del arte contemporáneo}

Algunos apuntes sobre la relación del cuerpo con la normatividad en las artes servirán para aportar elementos inspiradores desde otro ámbito interesante en el contexto que nos ocupa. No hay duda de que la presencia del cuerpo en las artes visuales ha experimentado cambios de gran calado en las últimas décadas.

Ramírez (2003) destaca que no ha sido precisamente la diferencia la que ha regido históricamente la relación entre cuerpo y normatividad en el arte, sino más bien el canon, la norma. Nos remite a la formulación de Winckelmann, que espera de la representación del cuerpo en las artes, nada menos que "una fusión de la fortaleza de la madurez con la alegría de la juventud". La imagen de los dioses es tan idéntica en los artistas griegos, afirma, como si la prescribiese alguna ley fijada en "las más hermosas estatuas" (citado en Ramírez, 2003: 21). Más o menos en las 
antípodas de la preocupación por los cuerpos canónicos, buena parte del arte contemporáneo se ha dedicado a problematizar la representación del cuerpo.

Una importante línea de indagación ha venido de la mano de las artistas relacionadas con las tendencias feministas de la segunda mitad del siglo XX. Precursoras como Judy Chicago plantearon ya reflexiones desde la óptica de las mujeres que no se reconocían en los cuerpos femeninos presentes en el arte y la cultura visual de su tiempo. Así, por ejemplo, en obras emblemáticas como Red Flag (1971) o Dinner Party (1974), las representaciones del cuerpo o de partes de la anatomía femenina tienen un contenido de género evidente. También las imágenes de Birth Project (1980-1985) presentan la experiencia del cuerpo desde vivencias inequívocamente femeninas como la gestación y el parto. Tampoco es reconocimiento en los cánones corporales lo que encontramos en Carolee Schneemann. En la performance Interior Scroll (1975), quizá su trabajo más conocido, extraía de su vagina un rollo de papel con frases relativas al sexismo patriarcal en el arte. Como en una negación del cuerpo como objeto de la mirada masculina se cubría el cuerpo de barro, pintura (Meat Joy, 1964), serpientes (Eyebody, 1963), etc. En una órbita similar podrían situarse las performances y fotografías de Cosey Fanni Tutti o las Body Series (1973) de Ana Mendieta. La transformación del cuerpo para distanciarlo voluntariamente de la normatividad ha estado presente en artistas como Hannah Wilke, en trabajos como Scarification Object Series (1974-1982), o, de modo más invasivo, en artistas como Stelarc o Orlan y sus innumerables acciones quirúrgicas sobre su propio cuerpo.

La nómina de artistas que, en las últimas décadas, han centrado su atención en proponer nuevas aproximaciones al cuerpo es amplísima. Muchas tienen un referente conceptual imprescindible en Judith Butler. Para Butler (2007), hay que repensar la relación entre cuerpo e identidad en un momento en que esta última es mutable, está en cambio permanente. En las sociedades premodernas se podía pensar en la identidad como un conjunto de parámetros que venían dados (Guiddens, 1994), como la familia, el clan, el territorio de origen, etc. Butler, en línea con tantos otros pensadores contemporáneos, considera que la identidad es hoy un proceso en constante cambio; no es algo fijo. Este carácter performático de la identidad afecta a la relación con el cuerpo. Así, por ejemplo, la anatomía no es determinante; el binarismo de género que hemos asumido como "normal" (si tal calificativo tiene algún sentido) es una construcción cultural. Las ideas de Buttler han tenido un efecto seminal en el trabajo de numerosos artistas y teóricos, entre los que cabría destacar a Paul B. Preciado, que se ha servido de términos como transfeminismo o pornopunk para propuestas que contienen una fuerte voluntad de rebeldía ante las imágenes de cuerpos supuestamente normativos (Preciado, 2009, 2014).

La vivencia del cuerpo se ha relacionado también, en el arte contemporáneo, con temas como la diversidad funcional, la lesión o la enfermedad. Enumeraremos solo algunos ejemplos especialmente elocuentes. Ángela de la Cruz, en sus esculturas, alude de modo sutil e impresionante a un tiempo, al cuerpo dañado, a partir de su experiencia tras un accidente vascular que afectó seriamente su movilidad. Antoni Abad, en proyectos como Canal Accesible (2006), plantea la diversidad funcional desde una visión de corte reivindicativo, en una propuesta de arte comunitario en que son los propios afectados los que cartografían las barreras 
arquitectónicas de la ciudad con que topan a diario sus sillas de ruedas. David Jay fotografía en Scar Project (2005-2016) a personas que asumen con una valentía admirable los cambios que ha sufrido su cuerpo tras sufrir un cáncer.

La lista de ejemplos podría ser mucho más extensa. Resulta sugerente, en cualquier caso, relacionar el espíritu cuestionador, crítico o autoexploratorio que anima buena parte de estas propuestas con los propósitos de la arteterapia. Comprobamos que tanto el arte contemporáneo como la arteterapia en contextos educativos han sido potentes vehículos de autoconocimiento, de exploración de la propia identidad en lo relativo al cuerpo, o de expresión y resolución del conflicto o el malestar.

\section{Experiencias sobre autorrepresentación y vivencia del cuerpo}

La experiencia pedagógica que relatamos en los párrafos que siguen responde a la línea argumental explicitada hasta aquí. Por un lado, pretendemos que las artes visuales sirvan de vehículo a la voluntad levinasiana de comprender la alteralidad como una manifestación de la diversidad de lo humano. Vemos en las artes visuales poderosas herramientas para cuestionar la alienación de las subjetividades a través de una normatividad que etiqueta y segrega. Comprobamos que existen numerosas experiencias en la creatividad artística del siglo XX y XXI que exploran diversos modos de relación con el cuerpo para poner sobre la mesa formas de control de las subjetividades en la cultura contemporánea. Un control que a menudo no es coercitivo, sino, como se ha apuntado, oblicuo e interiorizado en forma de normatividad o "normalidad".

Pensamos que todas estas ideas pueden y deben ser transferidas a la formación de los maestros de educación infantil y primaria, y la experiencia que proponemos se enmarca en tal propósito. Consideramos que es parte esencial de la formación de los docentes experimentar en primera persona procesos y estrategias relacionados con las artes y la creatividad que, después, deberán transferir al medio escolar. Por otro lado, una importante tradición de pedagogía crítica nos ha hecho tomar consciencia, en las últimas décadas, de la importancia de entender la docencia desde una perspectiva crítica y emancipatoria (Giroux, 2004; Kincheloe, 2008), perspectiva que, al ser consciente de la dimensión performática de la relación pedagógica, presta una nueva atención a los medios visuales y artísticos (Denzin, 2013; Hernández, 2010).

La investigación que referimos está claramente centrada en las artes, pero incorpora también aspectos de inspiración fenomenológico-hermenéutica. Como hemos visto, la relación cuerpo-identidad-subjetividad tiene una dimensión claramente fenomenológica. Se trata, en buena medida, de una relación de experiencia vivida. Como nos recuerda Van Manen (2003), damos sentido a la experiencia vivida al relatarla. La escritura, en Van Manen (también las imágenes y los medios artísticos, añadiríamos nosotros), son medios para poner en claro la experiencia, para recapitularla y explorar su significado. La investigación hermenéutica en educación se ha descrito como el intento de comprender las perspectivas de los seres humanos. Este comprender es situacional; por tanto, estudiamos en detalle la relación pedagógica en su contexto original. El propósito 
de comprender en contexto se opone a la voluntad de elicitar de normas universales, propia de otros paradigmas de investigación. La investigación hermenéutica es de corte claramente interpretativo. Entre sus objetivos figura el hacer explícito el conocimiento tácito o las teorías intuitivas que a menudo guían nuestra acción, aunque sea de modo inconsciente. La validez de una investigación hermenéutica, como interpretación, no depende exactamente del "acierto" de su planteamiento y conclusiones (Torbert, 1981). El investigador no pretende poner en claro "la verdad"; más bien debe plantearse si su forma de enmarcar las preguntas de investigación es realmente fructífera y significativa. Es decir, un criterio clave de validez sería considerar no solo si el planteamiento es "correcto", sino también si es útil o esclarecedor.

En nuestro caso, las preguntas de investigación pretendían enfocar los aspectos del proceso de trabajo que nos parecían más relevantes, y se podían sintetizar en cinco cuestiones:

¿Los participantes dan sentido a la experiencia vivida a través de la acción artística? ¿Es productiva para la interpretación de la experiencia vivida la complementariedad entre imágenes y relato escrito de la experiencia?

Las artes en el contexto de la formación de maestros, utilizadas como vehículos de autoconocimiento, autoexploración y autoaceptación, ¿dan lugar a procesos y resultados con un grado relevante de creatividad, expresividad y calidad artística?

¿Se pueden aducir indicios de que la experiencia realizada ha aportado, en algún sentido, un mayor grado de sensibilidad hacia la diversidad a partir de la consciencia de la propia particularidad?

¿Qué grado de implicación suscita la experiencia en los participantes? ¿Aportan los medios artísticos un potencial añadido de sinceridad o implicación? ¿Se evidencia de algún modo que el hecho de experimentar en primera persona la experiencia la hace más propia y pone a las participantes en mayor disposición de comprender su alcance y posibilidades?

¿Los participantes muestran haber entendido el alcance pedagógico potencial de las artes en relación con la autoconciencia y la autoaceptación? ¿Dan muestras de haber comprendido la relación de la experiencia con su futuro profesional como docentes?

La concreción metodológica, en este tipo de investigación, puede ser también poco convencional. Van Manen (2003: 48) llega a afirmar que "el método de la fenomenología hermenéutica es que no hay método". Sin embargo, como métodos empíricos, propone la descripción de experiencias personales, experiencias de otros e, incluso, obtención de descripciones en fuentes literarias; la entrevista conversacional, y la observación de proximidad. El investigador fenomenológico hermenéutico está interesado, en primer lugar, por el estudio del significado esencial de los fenómenos, así como por el sentido y la importancia que estos tienen (Ayala, 2008). En el caso de la investigación aplicada al campo educativo, el 
interés se orienta a la determinación del sentido y la importancia pedagógica de los fenómenos educativos vividos cotidianamente.

Una estrategia que ha funcionado a menudo como aliada de la investigación hermenéutica e interpretativa es la narración, el relato. Como hemos apuntado, relatar nuestra propia experiencia es, según Van Manen, un modo de fijar la perspectiva fenomenológica, una vía de acceso a la experiencia vivida tal como la experimentamos, sin apriorismos ni tomas de partido teórico previos. En la perspectiva narrativa, el investigador es a la vez narrador y narrado (Atkinson y Delamont, 2006). En vez de entenderse como reflexión analítica, transparente y comunicable, la narración es contextual, comunal, relacional; implica a sujetos individuales. No nos situamos como observadores externos, sino como personas en un diálogo con otros. La narratividad es un lugar de encuentro, y ese encuentro posibilita la construcción de la identidad y es un acto performático en común con otros.

La narración de la experiencia vivida, pues, nos es útil para releerla de forma interrogativa y analítica, al tiempo que constructiva. Según Stanley y Temple (2008), en parte, esto se logra mediante la comparación de los textos (escrito, hablado, visual...) con otros textos, relacionando los textos con los contextos de producción y consumo, y también a través de la perspectiva del tiempo transcurrido, cuando nos proporciona una nueva ubicación temporal. En la experiencia que presentamos, la representación de la identidad en relación con el cuerpo se plasmó a través de medios artísticos (fotografía, vídeo, performance, pintura). El lenguaje oral ayudó a dar significado a las propuestas, en una sesión de grupo en formato conversación posterior a la presentación de cada participante. Por su parte, el investigador observó in situ, como parte implicada, y documentó procesos con apuntes de campo y fotografías. Más tarde, los participantes reelaboraron su experiencia en un texto escrito que formó parte del portafolios del curso.

Las sucesivas vueltas sobre el tema sugieren un proceso en capas de lectura en una secuencia creciente de búsqueda de significación. Esta reelaboración se inspira en las ideas de reductio y vocatio (Van Manen, 2003). La primera se entendería como la intención de captar las estructuras esenciales de la experiencia a través de distintos modos de aproximación. Vocatio, por su parte, sería el conjunto de estrategias de escritura que usa el investigador para revelar de forma convincente la naturaleza y la importancia del fenómeno estudiado. Ayala (2008) propone una serie de etapas para organizar estas ideas: recoger la experiencia vivida, reflexionar acerca de la experiencia vivida, escribir-reflexionar acerca de la experiencia vivida.

En nuestro caso, sin embargo, una parte esencial del proceso se da a través de las propias artes visuales. Los medios artísticos nos abren enormes posibilidades para la investigación en temas como los que nos ocupan (Barone y Eisner, 2012; McNiff, 2013). Como ha expresado Kossak (2013:22),

“en la investigación basada en las artes, la experiencia fenomenológica se representa a través del propio acto creativo. La creación artística, independientemente del medio escogido (sonido, ritmo, movimiento, actuación, poesía, pintura) abre un espacio en que tanto el mundo como 
nuestro estar en él emerge en una totalidad única pero de una riqueza inagotable".

Para Kossak, la recogida de evidencias de carácter artístico está en el centro de la investigación en arteterapia. Abarca diversas formas de conocimiento, incluyendo las de carácter afectivo, sensorial, creativo, observacional e intuitivo, y no elude la experimentación, el riesgo, el descubrimiento y la creación de significado a través de la actividad artística. En el proceso se privilegian los aspectos relacionales e intersubjetivos, el entendimiento, el apoyo, la escucha atenta y el deseo genuino de dar espacio a los participantes.

En el caso que nos ocupa, los participantes acogieron con una mezcla de entusiasmo y curiosidad la posibilidad de realizar un trabajo artístico sobre la identidad y la autorrepresentación. Una primera fase del trabajo se entendió como indagación sobre el tema escogido. Los participantes recogieron información sobre trabajos artísticos relacionados con la autorrepresentación, la identidad y el cuerpo. Los resultados fueron objeto de una puesta en común enriquecedora para todo el grupo.

En una segunda fase se llevó a cabo una tutorización del proyecto creativo de cada participante: a partir de las ideas preliminares aportadas, se discutieron posibles enfoques y se puso en claro su concreción técnica. En esta fase se detectó la presencia de temas claramente relacionados con la diversidad y el cuerpo, como subtemas de la autorrepresentación.

El paso siguiente fue la presentación ante el grupo de la propuesta creativa de las participantes una vez realizada. Los miembros del grupo tenían la opción de no realizar esta presentación pública, aunque, finalmente, la voluntad de participar en ella fue unánime.

Posteriormente cada participante redactó un texto en que explicitó el modo en que había vivido su experiencia y el sentido que tenía para él o ella.

Entre los participantes, en 42 casos aparecen como definitorias de su autorrepresentación cuestiones vinculadas a la apariencia física o a la vivencia del cuerpo. El tema mayoritario entre ellas (32 casos) es sin duda la imagen social del cuerpo, el rechazo o la incomodidad ante los "cánones de belleza" presentes en los media y, de modo significativo, el peso y los trastornos de la conducta alimentaria. En ocho casos aparecen cuestiones relacionadas con dolencias, lesiones o cuestiones de salud que han marcado de una u otra forma su identidad. En dos casos, finalmente, se plantean temas de diversidad funcional y el proceso personal que ha comportado para ellas el hecho de asumirlos en el marco de una vida plena.

Los textos de reflexión sobre el proceso creativo tienen todos un tono claramente positivo. En los ejemplos que siguen, las referencias a las participantes no recogen sus nombres reales.

Muchos de los participantes reflejan las dificultades iniciales en el momento de abordar el trabajo. Abundan las descripciones de un momento inicial de duda o tanteo, como el que expresa Julia:

"tenía una idea general de cómo encarar el trabajo, pero el resultado no parecía que iba a ser algo que realmente mostrara mi yo más personal. Después de mucho pensar en ello, desestimé algunas posibilidades" 
Este tipo de dudas se suman, en algunos casos, a las dificultades que entraña el hecho de mostrarse ante los compañeros de clase:

"me sentí bastante perdida, porque aunque me gusta el arte y la estética, no encontraba nada que realmente me llamara la atención. Además, no quería que mi trabajo fuera demasiado personal, ya que no conocía mucho a la gente de mi grupo y no me era fácil abrirme”.

Otros participantes muestran, en cambio, una clara determinación:

"En el momento en que se nos propone realizar el trabajo creativo, tengo muy claro lo que necesito expresar, ya no como mera finalidad expresiva, hacia los otros, sino como trabajo propio, para mí mismo. Como si fuera una manera de afrontar el problema, parto de la intención de interpretarlo a través del arte. Un trabajo propio dirigido a entender, afrontar e interpretar la enfermedad."

Abundan los textos descriptivos del proceso de toma de decisiones. Se describen las dificultades y dudas afrontadas una vez decidida la idea que se quiere desarrollar, se detalla el procedimiento seguido, etc.

Marta, que sufrió un largo periplo de operaciones y problemas visuales a partir de una lesión ocular grave en su infancia, relata así su proceso:

"me costó mucho decidir cómo quería representar mi idea, hasta que poco a poco todo fue saliendo rodado. Tenía claro que haría alguna cosa relacionada con mis ojos, ya que a partir de una antigua lesión ocular, que me llevó casi a perder la vista, mis ojos tienen tras de sí una larga historia. Al cabo de unos días, la principal idea me vino a la mente: realizaría una composición con fotos de mis ojos $\mathrm{y}$, de fondo, una foto mía de pequeña, de aquella época. No acababa de ver clara la idea, y opté por primeros planos de mis ojos en diferentes etapas; pensé en imágenes en blanco y negro, pero más tarde opté por el color para que la composición no quedara tan oscura."

Andrea y Noa, motivadas por experiencias de su entorno familiar, tomaron como tema el cáncer en las mujeres. Realizaron una stop motion en que el aspecto ingenuo de una muñeca de trapo se contraponía a la seriedad del tema planteado. El personaje subía trabajosamente la escalera de una vieja iglesia:

"Hicimos un fotomontaje, con una muñeca de trapo que representaba una mujer enferma. La escalera de caracol inspira un camino largo y cansado, estrecho, claustrofóbico. La entrada tiene una puerta de hierro, pesada. Pero la llegada arriba es lo más gratificante que existe después de ese gran esfuerzo. Vimos enseguida la relación que existía entre la subida por la escalera de caracol y la superación de la enfermedad una vez salíamos, arriba, al exterior. Pusimos muchas ganas y mucho énfasis en transmitir 
todas estas emociones y sentimientos a todos los que vieran el vídeo. Creo que lo conseguimos."

Sin duda el aspecto más destacable de los textos escritos es el de haber ofrecido un espacio para dar sentido a la experiencia vivida. Queda claramente manifiesta la implicación personal. Los participantes expresan sin lugar a dudas que la actividad artística ha sido un camino para vehicular aspectos muy personales de la vivencia del cuerpo íntimamente relacionados con su identidad.

Marina relata su proceso de superación personal en relación con la espina bífida, que ha presentado a través de medios artísticos. Su creación fue una instalación artística en que una de sus férulas se cubrió de fotografías suyas en distintos momentos vitales, que representaban hitos conseguidos:

"Llevar aparatos, como las férulas, u otras cosas que he llevado a lo largo de la vida no es fácil psicológicamente por muchas cuestiones. No puedes comprar los zapatos que querrías, no te sientes del todo libre a la hora de caminar, pero pese a todo sigo adelante. Tengo la suerte de poder hacer muchísimas cosas y noto el suelo bajo mis pies. Me siento muy orgullosa. Haciendo este trabajo de las férulas pienso que he conectado con mi yo más íntimo. A través de la creatividad y multitud de sentimientos creo que me ha transportado a cada uno de los momentos que he pasado y me ha hecho ver el largo camino recorrido. Por eso he titulado mi trabajo «Ando». Quiero decir que, gracias a ese camino recorrido, ando con bastante libertad y puedo hacer cada vez más cosas."

Aunque la propuesta inicial estaba focalizada en la autorrepresentación, uno de los participantes centró su atención en una persona muy próxima, y en una situación que determinaba en esos momentos su propia realidad. El resultado fue un excelente trabajo multimedia de gran complejidad que denotaba un altísimo grado de compromiso con la propuesta inicial.

"la persona enferma es mi padre, y es necesario decirlo porque ha sido necesario un diálogo abierto en el conocimiento de su enfermedad. Si no fuera así, no me habría adentrado en la complejidad de esta obra (trabajo). No habría sentido la necesidad ni me habría sentido capaz de hacerlo."

Durante las sesiones en que se ponían en común los resultados de la indagación previa sobre artistas y cultura visual, anteriores a la realización del trabajo creativo, ya se puso de manifiesto el alcance emotivo de las propuestas. Como relata Anna, que aportó información sobre el trabajo del fotógrafo David Jay en el proyecto SCAR,

"La enfermedad implica ayudar a vivir los momentos más difíciles para las personas diagnosticadas. Ante el trabajo de SCAR, basado en fotografías tan reales de hombres y mujeres, tal como sentían la enfermedad y tal como se sentían ellos y ellas, vi que muchos de nosotros 
ignorábamos la realidad. En el momento de hacer la presentación oral ante mis compañeras, tuve que dejar de hablar, tenía los ojos inundados de tanta belleza y de lo mucho que me había servido esta representación artística para mi vida."

La posibilidad de relatar la experiencia vivida a través de medios artísticos conlleva el uso de metáforas que enfatizan la implicación personal a que nos estamos refiriendo. Joana nos cuenta así algunos aspectos del vídeo que realizó:

"enterré diversas imágenes que simbolizan aquello que se quiere olvidar. Puse una pluma de pájaro en cada agujero, símbolo de la fragilidad, pero también de la esperanza. Acabé la videocreación con una imagen que quería olvidar definitivamente. Por eso en el vídeo rompo en pedazos la fotografía en que se ve al paciente en el hospital, y, en este caso, me quedo la pluma como símbolo que me acompaña."

Finalmente, los textos recogen también la experiencia vivida en términos de valoración global, en particular por lo que se refiere a la nueva forma de entender la actividad artística y a la dimensión pedagógica que les ha aportado el trabajo. Los textos parecen evidenciar un cambio de perspectiva destacable.

"como conclusión final, quiero añadir que estas sesiones de trabajo han sido fantásticas para nuestra formación. En los años que llevamos de carrera, ha sido la primera vez en que hemos aprendido cosas que realmente podremos llevar a cabo en las aulas. Toda la parte creativa nos ha permitido experimentar y descubrir las ideas del resto de los compañeros. Ya tengo ganas de ponerlas en práctica."

"una vez finalizado el trabajo, coincidimos en la sensación de superación por nuestra parte. El resultado fue muy positivo para nosotras. Personalmente estoy muy orgullosa y dedico este stop motion a todo el mundo que necesite motivación para luchar contra la enfermedad."

"quisiera destacar la importancia de poder transmitir una idea, que puede ser incluso muy compleja y profunda, a través de una obra artística, y el hecho de contemplar el arte como una herramienta muy potente para cambiar el mundo."

"me llevo una muy buena sensación de este trabajo y de esta asignatura. He cambiado una idea muy negativa que tenía de mí misma en relación con las artes. Haciendo el trabajo he disfrutado y he visto que realmente todo el mundo tiene capacidad para trabajar el arte; solo hemos de despertar la creatividad que llevamos dentro. Espero que me sirva durante mi carrera profesional y agradezco este cambio en mi actitud y los aprendizajes adquiridos". 


\section{Conclusiones}

A lo largo de este artículo hemos insistido en la pertinencia de utilizar las artes como medio de autoconocimiento, en este caso centrado en la vivencia del cuerpo, en el contexto de los maestros y maestras en formación. Nuestros argumentos centrales han sido, por un lado, la necesidad de introducir en la labor docente la mayor sensibilidad posible ante la diversidad y la diferencia, como paso previo a la empatía y la solidaridad con el otro y su particularidad; un paso que debe darse ya en las aulas de educación primaria, espacio universal de socialización de niños y niñas en el que confluyen individuos diversos. Por otro lado, la convicción de que estamos en disposición de introducir en un proceso de enseñanza-aprendizaje aquello que hemos experimentado en nosotros mismos y por nosotros mismos. Como se ha encargado de fundamentar una amplia tendencia de investigación interpretativa, narrativa y fenomenológica en educación, la experiencia narrada en primera persona, la subjetividad asumida y explicitada, es un punto de partida imprescindible ante algunos retos pedagógicos. Por otro lado, no podemos obviar que la creatividad artística tiene su concreción definitiva en la práctica.

No podemos omitir tampoco las dificultades y riesgos de una investigación basada en las artes; probablemente, no nos queda otra opción que asumir abiertamente su carácter diferencial ante otras metodologías. Como señala McNiff (2013), algunas preguntas relevantes siguen abiertas. ¿Cómo podemos repensar la planificación y el funcionamiento sistemático de una investigación para favorecer la infinita variabilidad, la naturaleza espontánea e imprevisible de la experimentación artística, en la que los resultados pueden emerger al margen de cualquier idea preconcebida? ¿Cómo podría la investigación basada en las artes mirar más allá del sesgo personal sin verse constreñida por los procesos de investigación estandarizados y formalizados propios de otras disciplinas o paradigmas? En la medida en que los instrumentos de investigación definen la disciplina y sus posibilidades, el potencial de las artes está vinculado, según McNiff, al perfeccionamiento de los métodos insustituibles que nos ofrecen para la indagación.

En cualquier caso, la investigación nos reafirma en la intuición inicial de que las artes son un vehículo de enormes posibilidades para la explicitación e interpretación de la experiencia vivida. La vivencia del cuerpo aparece en las producciones visuales de los participantes con un alto grado de implicación personal. Las reflexiones escritas sobre la experiencia confirman con rotundidad esta idea. La autoexploración y la autoaceptación se mencionan a menudo, de forma explícita, como partes integrantes de su proceso creativo. Personas sin un especial bagaje de experiencia artística han sido capaces de utilizar dibujos, vídeos, fotografías y performances, desplegando un considerable grado de creatividad y expresividad, para compartir con los demás aspectos de su vivencia de la relación entre cuerpo e identidad.

Tanto las notas de campo del investigador como las reflexiones escritas parecen evidenciar que los referentes artísticos utilizados en la fase inicial del proyecto han sido útiles para hacer visible ante los participantes la relación entre cuerpo, identidad y creatividad artística. 
Los participantes manifiestan de modo recurrente que esta experiencia les ha aportado una nueva mirada sobre las artes en contextos escolares. Más allá de los trabajos al uso, centrados en técnicas o en aspectos formales del lenguaje plástico, declaran haber descubierto, a través de la práctica, las posibilidades de las artes visuales para cuestionar convenciones, promover la reflexión, el razonamiento y la mirada crítica; y también para el autoconocimiento, para dar forma visible a cuestiones tan básicas como quiénes somos y cómo nos sentimos.

La investigación confirma también la idoneidad de los textos escritos como medio para poner en claro la experiencia tal como fue vivenciada por los participantes. Desde las dudas o el proceso de tanteo iniciales hasta las inseguridades con el tema o el proceso seguido y su eventual recepción por parte de los compañeros y compañeras de curso, o la carga positiva de la experiencia como autoexploración (catarsis incluso en algún caso), los textos elaborados por los participantes desprenden en general una sinceridad y una implicación personal poco habituales en un trabajo académico convencional. Como hemos apuntado ya anteriormente, muchos de los participantes se plantean transferir este tipo de experiencias a ámbitos escolares.

Cabría destacar, finalmente, algo que no se recoge de modo tan claro en los textos ni en las evidencias gráficas o escritas, pero que sí se observaba en los rostros y el lenguaje no verbal de los participantes durante la exposición de los trabajos ante el grupo, y que el investigador apenas supo cómo anotar en sus notas de campo. Las artes como autoconocimiento en lo relativo al cuerpo nos abren también una puerta a la empatía y la solidaridad. En efecto, la empatía estuvo sin duda presente en la presentación en grupo de los trabajos. Como en una imprevista plasmación del concepto de rostro en Lévinas, demanda directa de empatía dirigida por un yo individual e irrepetible a cada uno de nosotros, cada presentación de trabajo creativo ante el grupo, acompañada de algunos comentarios del autor o autora, arrancaba invariablemente un sonoro aplauso de los compañeros de clase. Nos gustaría pensar que la experiencia ha ayudado a los maestros a poner en práctica, en su futuro profesional, un principio esencial de solidaridad que nos lleva a afirmar, como proclamaba ya hace siglos el antiguo saludo maya, "yo soy tú, tú eres yo".

\section{Referencias bibliográficas}

Allen, P. B. (2001): "Art making as a spiritual path: The open studio process as a way to practice art therapy", en RUBIN, J. A. (ed.), Approaches to art therapy: Theory and technique. Nueva York: Brunner-Routledge

Atkinson, A. y Delamont, S. (eds.) (2006): Narrative Methods. Londres: SAGE.

Ayala, R. (2008): "La metodología fenomenológico-hermenéutica de M. Van Manen en el campo de la investigación educativa. Posibilidades y primeras experiencias". Revista de Investigación Educativa, vol. 26, n. ${ }^{\circ} 2$, pp. 409-430.

Barone, T. y Eisner, E. W. (2012): Arts based research. Los Angeles: SAGE.

Butler, J. (2007): El género en disputa. El feminismo y la subversión de la identidad. Barcelona: Paidós. 
Delgado, M. (1998): "El derecho a la indiferencia". Artículo publicado en El País, el 15 de enero de 1998, recuperado en: http://manueldelgadoruiz.blogspot.com.es/2011/02/elderecho-la-indiferencia-articulo.html el 15/02/2016

Denzin, N. (2013): Strategies of qualitative inquiry. Thousand Oaks: SAGE Publications.

Duncan, N. (2007): "Trabajar con las emociones en arteterapia", en Arteterapia. Papeles de arteterapia y educación artística para la inclusión social, vol. 2, pp. 39-49.

Fernández, M. (2008): "Hacia una pedagogía de las diferencias desde los aportes de la propuesta de Paulo Freire", en Godotti, M., Gómez, M. V., Mafra, J. y

Fernandes DE Alencar, M. (comps.): Paulo Freire. Contribuciones para la pedagogía. Buenos Aires: CLACSO.

Freire, P. (1985): Pedagogía del oprimido. Buenos Aires: Siglo XXI.

Freire, P. (1997): Pedagogía de la autonomía. Buenos Aires: Siglo XXI.

Foucault, M. (1986): "Por qué hay que estudiar el poder: la cuestión del sujeto", en Álvarez-Uria, F. y Varela, J. (eds.): Materiales de sociología crítica. Madrid: La Piqueta.

Foucault, M. (2001): Estética, ética y hermenéutica. Barcelona: Paidós.

Giddens, A. (1994): Modernidad e identidad del yo. El yo y la sociedad en la época contemporánea. Barcelona: Península.

Giroux, H. A. (2004): Pedagogía y política de la enseñanza. México: Amorrortu.

Goffman, E. (2008): Estigma: la identidad deteriorada. Buenos Aires: Amorrortu

Hernández F. (2010): Educación y cultura visual. Barcelona: Octaedro.

Husserl, E. (1985): Meditaciones cartesianas. México: FCE.

Kincheloe, J. (2008): Pedagogía crítica: de qué hablamos, dónde estamos. Barcelona: Graó.

Kossak, M. (2013): “Art-based inquiry: that's what we do!”, en McNIFF, S. (ed.): Art as reseach. Chicago: Intellect Books.

Kramer, E. (1982): Terapia a través del arte en una comunidad infantil. Buenos Aires: Kapelusz.

Lévinas, E. (1993): Entre nosotros: ensayos para pensar en otro. Valencia: Pre-Textos.

López Fernández-Cao, M. (coord.) (2006): Creación y posibilidad. Aplicaciones del arte en la integración social. Madrid: Fundamentos.

Martínez, N. y López Fernández-Cao, M. (2004): Arteterapia y educación. Madrid: Consejería de Educación. Comunidad de Madrid.

Mcniff, S. (1992). Art as medicine: Creating a therapy of the imagination. Boston: Shambhala.

Mcniff, S. (ed.) (2013): Art as reseach. Chicago: Intellect Books.

Mèlich, J. C. (2010): Ética de la compasión. Barcelona: Herder.

Mèlich, J. C. y Bárcena, F. (2000): La educación como acontecimiento ético: natalidad, narración y hospitalidad. Barcelona: Paidós.

Nevado, M., Del Río, M. y Vallès, J. (2014): "Imágenes de la anorexia: una reflexión desde la educación artística”. Arte, Individuo y Sociedad, vol. 26, n. ${ }^{\circ} 3$, pp. 367-385.

Preciado, P. B. (2009): "Transfeminismo y micropolíticas del género en la era farmacopornográfica”. Artecontexto, n. ${ }^{\circ}$ 21, pp. 24-28

Preciado, P. B. (2014): Testo Yonqui. Barcelona: Espasa.

Ramírez, J. A. (2003): Corpus Solus. Para un mapa del cuerpo en el arte contemporáneo. Madrid: Siruela. 
Sartre, J. P. (2008): El ser y la nada: ensayo de ontología y fenomenología. Buenos Aires: Losada.

Skliar, C. (2002): ¿Y si el otro no estuviera ahí? Notas para una pedagogía (improbable) de la diferencia. Buenos Aires: Miño y Dávila.

Stanley, L. y Temple, B. (2008): "Narrative Methodologies: Subjects, Silences, ReReadings and Analyses", en VV.AA: Biographical Research. Londres: SAGE.

Torbert, W. R. (1981): "Why educational research has been so uneducational: The case for a new model of social science based on collaborative inquiry", en Reason, P. y Rowan, J. (eds.), Human inquiry (pp. 141-152). Nueva York: Wiley.

Van Manen, M. (2003). Investigación educativa y experiencia vivida. Ciencia humana para una pedagogía de la acción y de la sensibilidad. Barcelona: Idea Books.

\section{Obras referenciadas}

Abad, A. (2006): Canal Accesible (Intervención colaborativa en espacio público y propuesta net art) Barcelona: Centre d' Art Santa Mónica.

Chicago, J. (1971): Red Flag (Performance y fotolitografia). Los Angeles: Womanhouse.

Chicago, J. (1974): Dinner Part. (Instalación). Nueva York: Elizabeth A. Sackler Center for Feminist Art, Brooklyn Museum.

Chicago, J. (1980-1985): Birth Project . (pintura y bordado) Nueva York: Museum of Art and Design.

Jay, D. (2005-2016): Scar Project. (fotografia). Work in progress.

Mendieta, A. (1973): Body Series (performance y fotografia). Iowa: University of Iowa.

Schneemann, C. (1963): Eyebody (performance). Nueva York: Artist's Studio.

Schneemann, C. (1964): Meat joy (performance). París: Festival of Free Expression.

Schneemann, C. (1975): Interior Scroll (performance). Exposición Women Here and Now, Nueva York: East Hampton Contemporary Art.

Wilke, H. (1974): Scarification Object Series (fotografia). Los Angeles: Women's Building 